\title{
Fate of lipid vesicles in vivo: A gamma-ray perturbed angular correlation study
}

\author{
(liposomes/drug-delivery system/rotational correlation time/gamma-ray probe)
}

\author{
Karl J. Hwang* and Marcia R. Mauk \\ Division of Chemistry and Chemical Engineering, Arthur Amos Noyes Laboratory of Chemical Physics, California Institute of Technology, Pasadena, \\ California 91125 \\ Communicated by John D. Baldeschwieler, August 12, 1977
}

\begin{abstract}
The structural integrity of unilamellar vesicles has been studied in vitro and in vivo by use of gamma-ray perturbed angular correlation techniques. These studies utilize lin In $^{3+}$ weakly bound to the chelator nitrilotriacetic acid as a probe to monitor the percentage of intact vesicles. When complexes of ${ }^{111} \mathrm{In}^{3+}$ and nitrilotriacetic acid is encapsulated in vesicles, ${ }^{111} \mathrm{In}^{3+}$ exhibits a fast tumbling rate. Upon alteration of the membrane, ${ }^{111} \mathrm{In}^{3+}$ is released from the liposomes and becomes bound to macromolecules, consequently exhibiting a decrease in ${ }^{111} \mathrm{In}^{3+}$ tumbling rate. The in vitro experiments show that the present technique is capable of determining quantitatively the percentage of material released from the vesicles upon the addition of serum or Triton X-100 to vesicles. The percentage of vesicles remaining intact in vivo can also be monitored continuously by the present technique. In mice, the half-life of dipalmitoyl phosphatidylcholine-cholesterol vesicles after intraperitoneal injection was estimated to be 10-13 hr. The present study suggests that the vesicles remain intact in various tissues for extended periods, thereby allowing a slow release of the encapsulated material at those sites.
\end{abstract}

Therapeutic agents encapsulated in liposomes have been successfully applied to model systems as diverse as enzyme replacement therapy (1-3), heavy metal detoxification (4), and cancer chemotherapy (5). The increasing interest in the potential of liposomes as carriers for pharmacologically active agents is demonstrated by several recent reviews (6-9). Answers to the pervading problem of how to bring functional molecules into contact with a specific target in a controlled fashion must be sought through systematic investigations of optimal liposome size, structure, and membrane composition. Throughout these investigations, it is essential to know whether the administered liposomes remain intact. Indium-111 entrapped in liposomes is ideally suited for this purpose because radioisotope tracer methods can be used to determine the physical location of ${ }^{111} \mathrm{In}$, and the structural integrity of the liposomes can be monitored in vivo by gamma-ray perturbed angular correlation (PAC) studies.

The PAC technique as used in these studies monitors changes in the rotational correlation time of the ${ }^{111}$ In ion (10-12). Two gamma rays are emitted in cascade from the radioactive ${ }^{111}$ In nucleus and are detected by a coincidence spectrometer. The coincidence counting rate depends strongly on the angle between the directions of propagation of the gamma rays. This angular correlation may be perturbed by interaction of the radioactive nucleus with its environment. Thus, PAC studies can provide information concerning changes in the tumbling rate of ${ }^{111}$ In ions bound to molecules with different rotational correlation times.

The strategy adopted for determining the intactness of li-

The costs of publication of this article were defrayed in part by the payment of page charges. This article must therefore be hereby marked "advertisement" in accordance with 18 U. S. C. $\$ 1734$ solely to indicate this fact. posomes in vivo is based on the principle that ${ }^{111} \mathrm{In}^{3+}$ encapsulated in a liposome will exhibit a fast tumbling rate. However, upon alteration of the structural integrity of the membrane, the ${ }^{111} \mathrm{In}^{3+}$ will be released from the liposome and should rapidly become bound to protein, consequently exhibiting a decreased ${ }^{111} \mathrm{In}^{3+}$ tumbling rate. A chelator, nitrilotriacetic acid (NTA), was added to the buffers during vesicle formation to minimize binding of the trivalent cations to phospholipid headgroups.

\section{MATERIALS AND METHODS}

L- $\alpha$-Dipalmitoyl phosphatidylcholine (DPPC) purchased from GIBCO and cholesterol from Matheson, Coleman and Bell were used as supplied. The trisodium salt of NTA was obtained from Aldrich Chemical Co. Fresh rabbit serum was prepared from the blood of healthy New Zealand White rabbits by allowing blood collected from an ear vein to clot for $30 \mathrm{~min}$ at room temperature. The clotted blood was centrifuged at $2500 \times g$, $4^{\circ}$, for $20 \mathrm{~min}$; the serum was collected and refrigerated immediately.

Carrier-free ${ }^{111} \mathrm{InCl}_{3}$ in $0.05 \mathrm{M} \mathrm{HCl} / 0.9 \% \mathrm{NaCl}$ was obtained from Medi + Physics, Glendale, CA. The ${ }^{111} \mathrm{InCl}_{3}$ was purified from the saline and other contaminants by chromatography on Bio-Rad AG 1X-8 $(0.7 \times 10 \mathrm{~cm}$ column $)$ in $0.1 \mathrm{M} \mathrm{HCl}$. The fractions were collected in Nalgene beakers and taken to dryness under heat lamps. ${ }^{111} \mathrm{In}^{3+}$ was complexed to NTA by the addition of $0.9 \% \mathrm{NaCl} / 5 \mathrm{mM}$ sodium phosphate, $\mathrm{pH} 7.4\left(\mathrm{P}_{\mathrm{i}} /\right.$ $\mathrm{NaCl}$ ) containing $1 \mathrm{mM} \mathrm{NTA}$ to the ${ }^{111} \mathrm{InCl}_{3}$.

Preparation of Vesicles. Unilamellar vesicles were prepared from DPPC and DPPC-cholesterol, 2:1, (mol/mol). DPPC vesicles were prepared by addition of $1.0 \mathrm{ml}$ of a solution containing $1-2 \mathrm{mCi}$ of ${ }^{111} \mathrm{In}^{3+}$ in $1 \mathrm{mM} \mathrm{NTA} / \mathrm{P}_{\mathrm{i}} / \mathrm{NaCl}$ to $54 \mu \mathrm{mol}$ of solid DPPC in a small conical tube. For the DPPC-cholesterol vesicles, the DPPC $(27 \mu \mathrm{mol})$ and cholesterol $(13.5 \mu \mathrm{mol})$ were dissolved in chloroform and dried to a thin film at $42^{\circ}$ under a stream of nitrogen; then $0.5 \mathrm{ml}$ of a solution containing $1-2 \mathrm{mCi}$ of ${ }^{111} \mathrm{In}^{3+}$ in $1 \mathrm{mM} \mathrm{NTA} / \mathrm{P}_{\mathrm{i}} / \mathrm{NaCl}$ was added. The tubes were shaken briefly by a Vortex mixer and placed into a Branson sonicator with a titanium microtip. Sonication was carried out for $15 \mathrm{~min}$ at high power in a glycerol bath. The vesicle suspension was then centrifuged for $15 \mathrm{~min}$ at $300 \times \mathrm{g}$, $25^{\circ}$, for $30 \mathrm{~min}$ to remove any titanium fragments and highly aggregated material. The supernatant was clear for DPPCcholesterol preparations.

${ }^{111} \mathrm{In}^{3+}$ not entrapped in the liposomes was removed by

Abbreviations: PAC, gamma-ray perturbed angular correlation; NTA, nitrilotriacetic acid; DPPC, L- $\alpha$-dipalmitoyl phosphatidylcholine; $\mathrm{P}_{\mathrm{i}} / \mathrm{NaCl}$, phosphate-buffered saline $(0.9 \% \mathrm{NaCl} / 5 \mathrm{mM}$ sodium phosphate, pH 7.4); $\left\langle\mathrm{G}_{22}(\infty)\right\rangle$, time-integrated perturbation factor.

* Present address: Department of Pharmaceutical Sciences, School of Pharmacy, University of Washington, Seattle, WA 98195. 


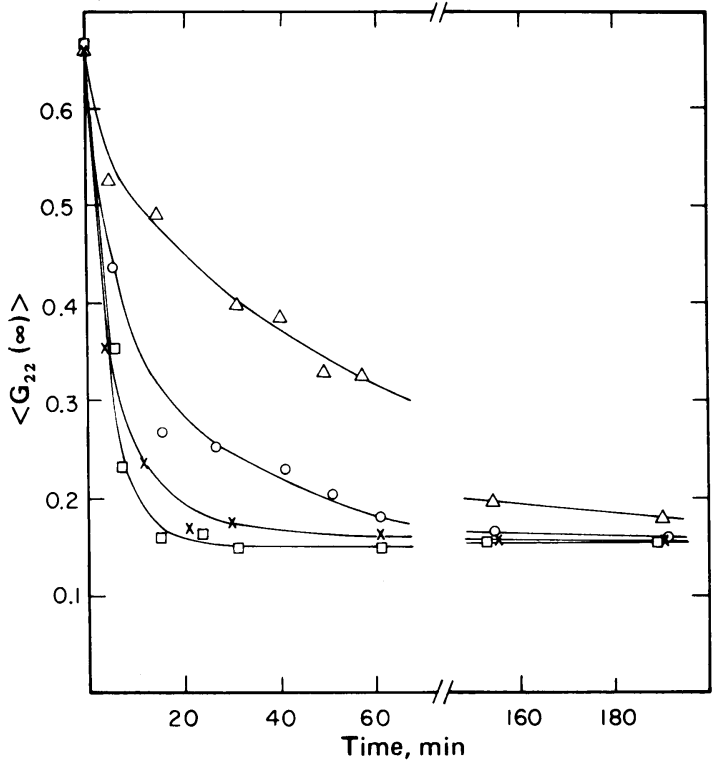

FIG. 1. Kinetics of binding of ${ }^{111} \mathrm{In}^{3+}$ by serum: $\left\langle\mathrm{G}_{22}(\infty)\right\rangle$ as a function of time. All samples contained $0.15 \mathrm{ml}$ of fresh rabbit serum, $0.05 \mathrm{ml}$ of saline, and the following final concentrations of NTA: $\square$, $0.25 \mathrm{mM} ; \times, 0.050 \mathrm{mM} ; 0,0.75 \mathrm{mM} ; \Delta, 1 \mathrm{mM}$. Each sample contained $16 \pm 1 \mu \mathrm{Ci}$ of ${ }^{111} \mathrm{In}^{3+}$.

passage of the vesicle suspension over two $0.5 \times 7 \mathrm{~cm}$ Chelex100 (Bio-Rad) columns that had previously been equilibrated with $\mathrm{P}_{\mathrm{i}} / \mathrm{NaCl}$. Any remaining external ${ }^{111} \mathrm{In}^{3+}$ was removed by subsequent passage of the vesicles over a $0.8 \times 35 \mathrm{~cm}$ column of Sephadex G-50 (Sigma) in $\mathrm{P}_{\mathrm{i}} / \mathrm{NaCl}$. The vesicles were collected in the void volume of the column. Radioactivity in column fractions was monitored with a Nuclear Chicago well-type gamma-ray spectrometer. Typically, trapping efficiencies of $2-3 \%$ were observed. Leakage of ${ }^{111} \mathrm{In}^{3+}$ from the vesicles was subsequently assessed by dialysis of the vesicle preparations at $25^{\circ}$ against $1 \mathrm{mM} \mathrm{NTA} / \mathrm{P}_{\mathrm{i}} / \mathrm{NaCl}$ and by chromatography on Sepharose 4B (Pharmacia) in $0.95 \%$ sodium citrate $/ 0.65 \%$ $\mathrm{NaCl} / 0.02 \% \mathrm{NaN}_{3}, \mathrm{pH}$ 5.2. For Sepharose chromatography, the $0.7 \times 70 \mathrm{~cm}$ matrix bed included a $60-\mathrm{cm}$ section packed with 4-mm glass beads.

In Vitro Studies. The binding of ${ }^{111} \mathrm{In}^{3+}$ to NTA and to serum proteins was examined by PAC measurements carried out with a gamma-ray coincidence spectrometer (10). The kinetics of binding of ${ }^{111} \mathrm{In}^{3+}$ to serum proteins in the presence of various concentrations of NTA was monitored by measuring the time-integrated perturbation factor $\left[\left\langle\mathrm{G}_{22}(\infty)\right\rangle\right]$ of solution containing $16 \pm 1 \mu \mathrm{Ci}$ of ${ }^{111} \mathrm{In}^{3+}$. The decrease in the rotational correlation time of the ${ }^{111} \mathrm{In}^{3+}$ accompanying binding of the ${ }^{111} \mathrm{In}^{3+}$ to protein is evidenced by this measurement. The size of the radioactive source was considered in processing all data, with measurements being corrected to the level of $0.20 \mathrm{ml}$ in a $10 \times 75 \mathrm{~mm}$ glass tube.

The effect of serum on the permeability of vesicles containing ${ }^{111} \mathrm{In}^{3+}$ was investigated by measuring the change in $\left\langle\mathrm{G}_{22}(\infty)\right\rangle$ with time after the addition of fresh rabbit serum to the vesicle preparations. After extended periods of incubation at $25^{\circ}$ in the presence of serum, these vesicle preparations were chromatographed on Sepharose 4B to confirm the extent of leakage of ${ }^{111} \mathrm{In}^{3+}$ from the vesicles. When complete release of the entrapped NTA- ${ }^{111} \mathrm{In}^{3+}$ complex was desired, the vesicles were disrupted by the addition of chloroform or Triton X-100, or both.

In Vivo Studies. BALB/c mice from Jackson Laboratories (Bar Harbor, ME) and C57BL/6 mice bred at California In-
Table 1. Values of $\left\langle\mathrm{G}_{22}(\infty)\right\rangle$ for ${ }^{111} \mathrm{In}^{3+}$ in various environments*

\begin{tabular}{lcc} 
& \multicolumn{2}{c}{$\left\langle\mathrm{G}_{22}(\infty)\right\rangle$} \\
\cline { 2 - 3 } Sample & $\begin{array}{c}\text { Without } \\
\text { serum }\end{array}$ & $\begin{array}{c}\text { With } \\
\text { serum }\end{array}$ \\
\hline $\begin{array}{l}\text { NTA- }{ }^{111} \text { In }^{3+} \text { complex } \\
\text { DPPC vesicles containing }\end{array}$ & $0.68 \pm 0.02$ & $0.18 \pm 0.02$ \\
NTA-111 In & & \\
DPPC-cholesterol vesicles & $0.50 \pm 0.02$ & $0.35 \pm 0.02$ \\
containing NTA- ${ }^{111}$ In $^{3+}$ & $0.64 \pm 0.02$ & $0.60 \pm 0.02$ \\
\hline
\end{tabular}

* All samples in $\mathrm{P}_{\mathrm{i}} / \mathrm{NaCl}$ prior to the addition of 1 volume of fresh rabbit serum.

stitute of Technology were used for the in vivo studies. Administration of ${ }^{111} \mathrm{In}^{3+}$ to the mice was by intraperitoneal injection. In vivo PAC studies, using $16 \pm 2 \mu \mathrm{Ci}$ of ${ }^{111} \mathrm{In}^{3+}$ per mouse, were accomplished by placing the live mouse in the barrel of a modified plastic syringe centered in the spectrometer (13). After measurement of the $\left\langle\mathrm{G}_{22}(\infty)\right\rangle$ of the mouse for periods of up to $3 \mathrm{hr}$, the animal was returned to its cage. Additional measurements were performed at varying intervals during the 3 days after injection of vesicles containing ${ }^{111} \mathrm{In}^{3+}$.

The tissue distribution of ${ }^{111} \mathrm{In}^{3+}$ after intraperitoneal administration of ${ }^{111} \mathrm{In}^{3+}$-vesicles $(0.1 \mathrm{ml}$ of vesicle suspension containing $3.5 \mu \mathrm{Ci}$ of entrapped NTA- ${ }^{111} \mathrm{In}^{3+}$ per mouse) was examined. After varying lengths of time, the mice were killed by cervical dislocation followed immediately by decapitation. Organs and tissues were washed with $0.9 \% \mathrm{NaCl}$, blotted, and weighed. The distribution of injected radioactivity was determined by assaying the tissue samples in a well-type gamma-ray spectrometer.

\section{RESULTS}

In Vitro Experiments. Measurement of $\left\langle\mathrm{G}_{22}(\infty)\right\rangle$ of the sequentially emitted 173- and $247-\mathrm{keV}$ gamma rays of ${ }^{111}$ In provides a convenient method of estimating the rotational correlation time of the molecule to which the ${ }^{111} \mathrm{In}$ ion is bound (12). Values of $\left\langle\mathrm{G}_{22}(\infty)\right\rangle$ for ${ }^{11} \mathrm{In}^{3+}$ in various environments are shown in Table 1. A rapid tumbling rate (e.g., ${ }^{111} \mathrm{In}^{3+}$ complexed to the low molecular weight NTA) is characterized by a relatively high $\left\langle\mathrm{G}_{22}(\infty)\right\rangle$ value. In contrast, ${ }^{111} \mathrm{In}^{3+}$ bound to serum proteins exhibits a slow tumbling rate as characterized by a low $\left\langle\mathrm{G}_{22}(\infty)\right\rangle$ value. NTA was found to be a suitable chelator because at a final concentration of $1 \mathrm{mM}$ it decreased the extent of binding of ${ }^{111} \mathrm{In}^{3+}$ to lipid headgroups and still allowed binding of ${ }^{111} \mathrm{In}^{3+}$ to serum proteins. The kinetics of binding of ${ }^{111} \mathrm{In}^{3+}$ by serum at various final concentrations of NTA is shown in Fig. 1. At the lower concentrations of NTA (e.g., 0.25 $\mathrm{mM}$ ), most of the ${ }^{111} \mathrm{In}^{3+}$ became bound to serum proteins within $10 \mathrm{~min}$. This indicates that rupture of vesicles containing NTA- ${ }^{111} \mathrm{In}^{3+}$ should result in a decrease in NTA concentration sufficient to allow complete binding of ${ }^{111} \mathrm{In}^{3+}$ by protein within the time necessary to complete a PAC measurement.

The data in Table 1 also show that lower $\left\langle\mathrm{G}_{22}(\infty)\right\rangle$ values were obtained for NTA- ${ }^{111} \mathrm{In}^{3+}$ entrapped in vesicles than for the NTA- ${ }^{111} \mathrm{In}^{3+}$ complex alone. This indicates competitive binding of ${ }^{111} \mathrm{In}^{3+}$ to NTA and to the lipid headgroups on the inner surface of the vesicle. The degree of binding of ${ }^{111}$ In ions to the lipid headgroups will depend on the relative binding constants and on the local concentration of headgroups inside the vesicle. Thus, the lower value of $\left\langle\mathrm{G}_{22}(\infty)\right\rangle$ observed for DPPC vesicle preparations suggests that the average size of DPPC vesicles is smaller than that of DPPC-cholesterol vesicles. 


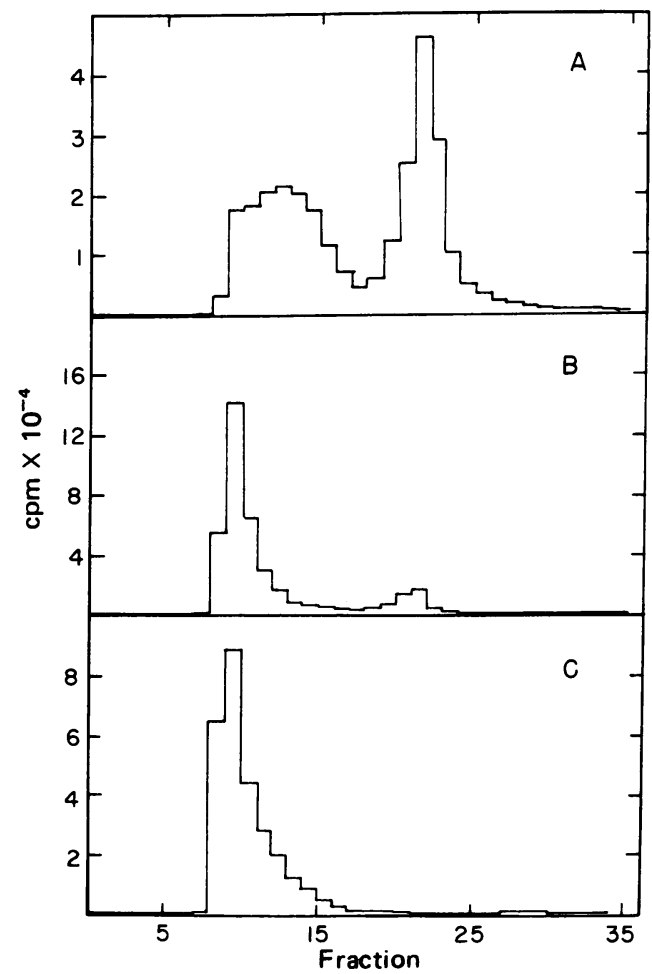

FIG. 2. The effect of serum on vesicle integrity as assessed by Sepharose 4B chromatography. $(A)$ One milliliter of serum/DPPC vesicles, 1:1 ( $\mathrm{vol} / \mathrm{vol})$, after incubation of the mixture for $53 \mathrm{hr}$ at $25^{\circ}$. (B) One milliliter of serum/DPPC-cholesterol vesicles, 1:1 (vol/vol) after incubation for $41 \mathrm{hr}$ at $25^{\circ}$. (C) Control incubation $0.8 \mathrm{ml}$ of DPPC-cholesterol vesicles after $66 \mathrm{hr}$ at $25^{\circ}$ in the absence of serum. The $1.0-\mathrm{ml}$ fractions were collected at a flow rate of $8 \mathrm{ml} / \mathrm{hr}$ from the $0.7 \times 70 \mathrm{~cm}$ column. Fractions $9-10$ represent the void volume; fractions 18-22 are the elution volume of serum proteins.

This is supported by the results of the gel filtration studies (Fig. 2). DPPC-cholesterol vesicle preparations were shown by electron microscopy and analytical ultracentrifugation to be heterogeneous in size with a mean diameter of $650 \AA$. These preparations contained less than $10 \%$ multilamellar liposomes.

The structural stability of our vesicle preparations was examined by dialysis of representative preparations of DPPC vesicles and DPPC-cholesterol vesicles. These measurements indicated leakages of $3.0 \%$ and $2.2 \%$, respectively, in $24 \mathrm{hr}$ at $25^{\circ}$, thus showing that they are of comparable stability in physiological salt solutions. Addition of rabbit serum, however, affected the permeability of the two types of vesicles to different extents (Table 1; Fig. 2). The percentage of ${ }^{111} \mathrm{In}^{3+}$ bound to serum proteins can be calculated by using the following expression (10):

$$
\left\langle\mathrm{G}_{22}(\infty)\right\rangle=x\left\langle\mathrm{G}_{22}(\infty)\right\rangle_{f}+(1-x)\left\langle\mathrm{G}_{22}(\infty)\right\rangle_{b}
$$

in which $x$ is the mole fraction of ${ }^{111} \mathrm{In}^{3+}$ remaining entrapped within the vesicles, $\left\langle\mathrm{G}_{22}(\infty)\right\rangle_{f}$ is the time integrated perturbation factor of NTA-111 $\mathrm{In}^{3+}$ inside the vesicles, and $\left\langle\mathrm{G}_{22}(\infty)\right\rangle_{b}$ is the factor of ${ }^{111} \mathrm{In}^{3+}$ bound to protein. By using Eq. 1 and the data in Table 1, the percentage of ${ }^{111} \mathrm{In}^{3+}$ bound to proteins is $47 \%$ for the DPPC vesicles and 9\% for the DPPC-cholesterol vesicles after incubation with fresh rabbit serum. These values are in good agreement with the results of gel filtration (Fig. 2 $A$ and $B$ ) which show $47 \%$ and $12 \%$ binding of ${ }^{111} \mathrm{In}^{3+}$, respectively.

The rate of leakage of ${ }^{111} \mathrm{In}^{3+}$ from DPPC vesicles in the

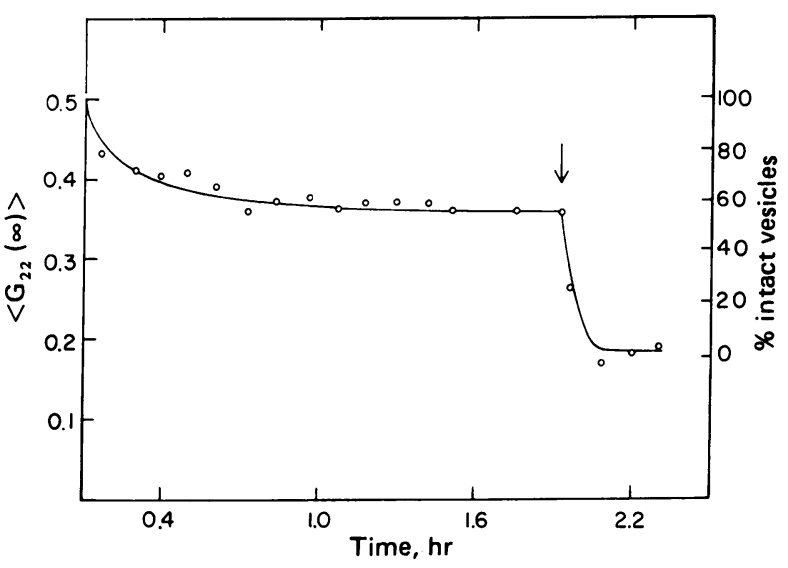

FIG. 3. Effect of serum on the structural integrity of DPPC vesicles. $\left\langle G_{22}(\infty)\right\rangle$ was monitored after addition of 1 volume of fresh rabbit serum to DPPC vesicles in $\mathrm{P}_{\mathrm{i}} / \mathrm{NaCl}$. The arrow indicates the addition of Triton X-100 to a final concentration of $0.2 \%$. The percentage of vesicles remaining intact was calculated by using Eq. 1 (see text).

presence of serum was examined by PAC (Fig. 3). It appears that rapid leakage of ${ }^{111} \mathrm{In}^{3+}$ is confined to the early period of the incubation. This suggests that there may be distinct populations of vesicles in our preparations. Addition of Triton X-100 to a final concentration of $0.2 \%$ led to rapid disruption of all the DPPC vesicles and binding of the ${ }^{111} \mathrm{In}^{3+}$ by serum. Serum was found to have a less marked effect on DPPC-cholesterol vesicles. Furthermore, the addition of $5 \%$ chloroform, in addition to the $0.2 \%$ Triton, was necessary to completely disrupt DPPC-cholesterol vesicles.

In Vivo Experiments. The greater stability of DPPC-cholesterol vesicles in the presence of serum made them suitable for in vivo measurements. The rate at which these vesicles, injected intraperitoneally, underwent structural alterations sufficient to cause leakage of ${ }^{111} \mathrm{In}^{3+}$ is shown in Fig. 4. The curves represent different strains of mice and separate preparations of DPPC-cholesterol vesicles. However, both give similar patterns for vesicle destruction, with $50 \%$ disruption occuring in 10-13 hr. Based on counting rates, it was determined that the ${ }^{111} \mathrm{In}^{3+}$ was being excreted from the mice at approximately $5 \%$ of the injected dose every $24 \mathrm{hr}$.

The PAC measurements give us an indication of the overall integrity of the injected vesicles. Further information regarding their fate was obtained from tissue radioactivity distribution studies. The data in Fig. 5 indicate that the intraperitoneally injected DPPC-cholesterol vesicles were rapidly removed from the injection site via abdominal lymphatics with subsequent drainage into the venous system and distribution throughout the mouse by way of the circulation. The amount of ${ }^{111} \mathrm{In}^{3+}$ in the blood increased rapidly such that $50 \%$ of the recovered ${ }^{111} \mathrm{In}^{3+}(42 \%$ of injected dose $)$ was in the blood at $2.5 \mathrm{hr}$ after injection. Similar blood radioactivity levels have been observed after intraperitoneal injection of other sonicated liposomes (14). Coincident with the increase in ${ }^{111} \mathrm{In}^{3+}$ in the blood, a decrease in the ${ }^{111} \mathrm{In}^{3+}$ recovered with the skin was observed. At $2.5 \mathrm{hr}$ only $16 \%$ of the recovered radioactivity (14\% of the injected dose) was found in the liver. At the later time points, (e.g., 29.5 $\mathrm{hr}$ ), almost complete removal of ${ }^{111} \mathrm{In}^{3+}$ from the blood had occurred and the liver had become the major site for ${ }^{111} \mathrm{In}^{3+}$ recovery. Less than $0.3 \%$ of the ${ }^{111} \mathrm{In}^{3+}$ was detected in the brain at any time point.

Comparison of PAC data (Fig. 4) with information at early time points of the tissue distribution studies indicates that little destruction of the DPPC-cholesterol vesicles occurred during 


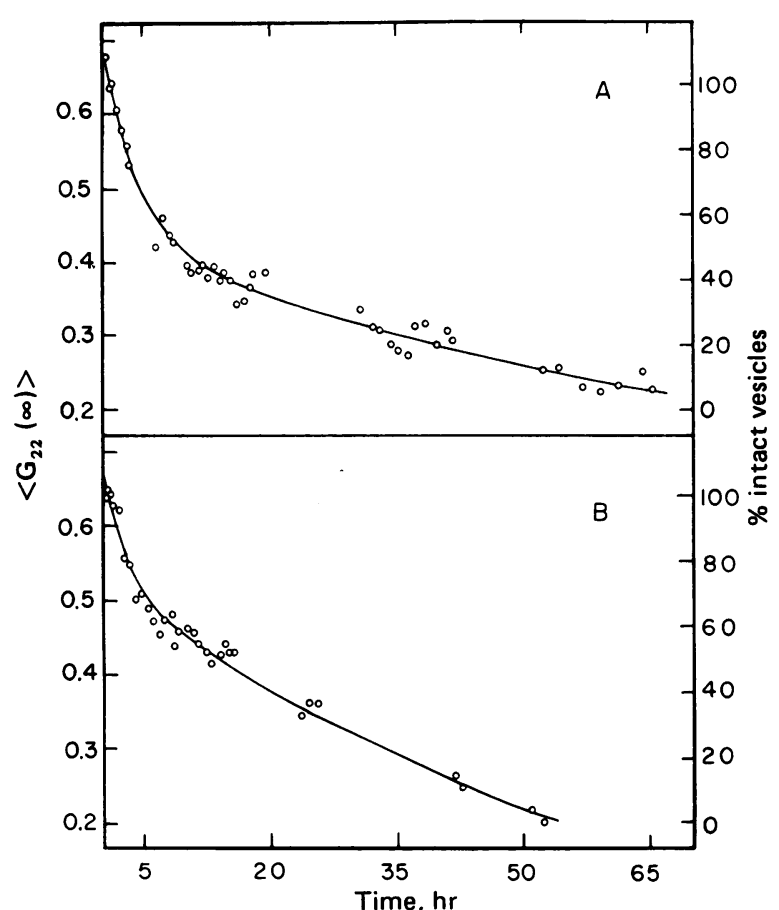

FIG. 4. Loss of structural integrity of DPPC-cholesterol vesicles in vivo after intraperitoneal injection into mice. The percentage of vesicles remaining intact was calculated from $\left\langle\mathrm{G}_{22}(\infty)\right\rangle$ by using Eq. 1 (see text). (A) Administration of $0.40 \mathrm{ml}$ of DPPC-cholesterol vesicles in $\mathrm{P}_{\mathrm{i}} / \mathrm{NaCl}$ containing $15 \mu \mathrm{Ci}$ of entrapped ${ }^{111} \mathrm{In}^{3+}$ to a $16-\mathrm{g}$ C57BL/6 mouse. (B) Administration of $0.35 \mathrm{ml}$ of DPPC-cholesterol vesicles in $\mathrm{P}_{\mathrm{i}} / \mathrm{NaCl}$ containing $14 \mu \mathrm{Ci}$ of entrapped ${ }^{111} \mathrm{In}^{3+}$ to a $18.5-\mathrm{g}$ $\mathrm{BALB} / \mathrm{c}$ mouse.

uptake of the liposomes from the site of injection. Two lines of evidence suggest that the vesicles remain intact in the bloodstream. The first is based on the nearly complete removal of ${ }^{111} \mathrm{In}^{3+}$ from the blood within $24 \mathrm{hr}$. If vesicle destruction had occurred in the circulation, the ${ }^{111} \mathrm{In}^{3+}$ would have bound to serum proteins, mainly transferrin $(13,15)$, and consequently be retained in the blood for extended periods of time. Furthermore, the PAC measurements show that $\sim 80 \%$ of the vesicles remained intact $3 \mathrm{hr}$ after vesicle administration.

The amount of radioactivity found in the liver increased steadily during the first $17 \mathrm{hr}$, as expected, after administration of small vesicles (16). This suggests that the DPPC-cholesterol vesicles were cleared from the blood and taken up by the liver. It is noteworthy that PAC measurements showed $~ 35 \%$ of the vesicles remaining intact $17 \mathrm{hr}$ after injection (Fig. $4 A$ ) but only $6 \%$ of the radioactivity was in the blood at that time according to tissue radioactivity distribution. This suggests that there were intact vesicles lodged in body tissues. The contents of these vesicles were slowly released as indicated by the further decrease in the percentage of intact vesicles remaining in the mice (Fig. 4) and the constant radioactivity levels in various tissues (Fig. 5).

Our results indicate that encapsulation in DPPC-cholesterol vesicles affords considerable protection of the ${ }^{111} \mathrm{In}^{3+}$ from interaction with tissues and biological fluids. This was further substantiated by examining the fate of ${ }^{111} \mathrm{In}^{3+}$ in $1 \mathrm{mM} \mathrm{NTA} /$ $\mathrm{P}_{\mathrm{i}} / \mathrm{NaCl}$ injected intraperitoneally into mice. Immediately after the injection, the $\left\langle\mathrm{G}_{22}(\infty)\right\rangle$ fell to $0.21 \pm 0.02$ and remained steady over the next $2.5 \mathrm{hr}$. Tissue examinations on mice sacrificed $2.6 \mathrm{hr}$ after intraperitoneal injection of $\mathrm{NTA} /{ }^{111} \mathrm{In}^{3+}$ showed $0.2 \%$ of the ${ }^{111} \mathrm{In}^{3+}$ in the blood and $0.4 \%$ in the skin. More than $93 \%$ of the ${ }^{111} \mathrm{In}^{3+}$ was recovered with the intestine

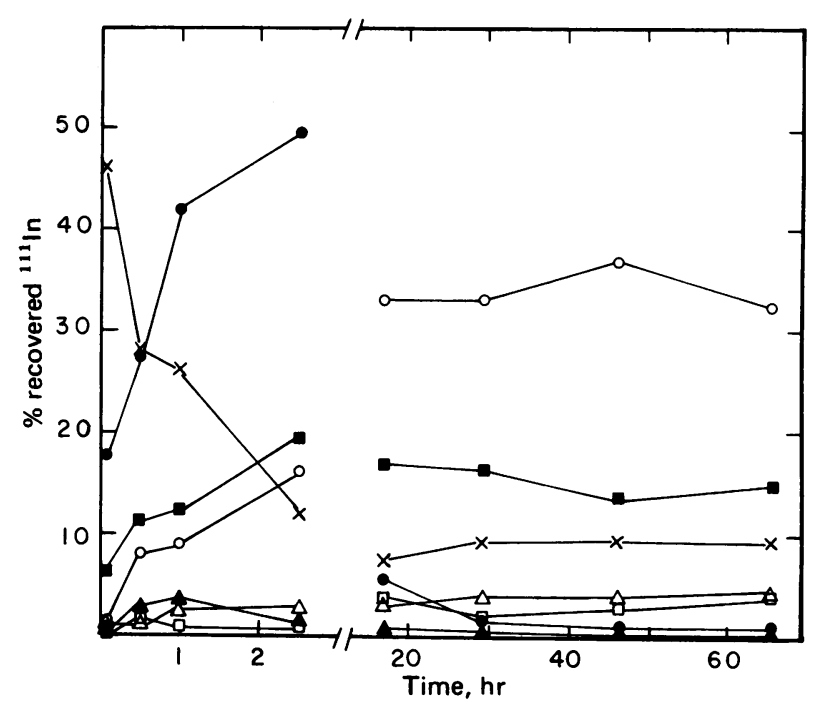

FIG. 5. Tissue distribution of ${ }^{111} \mathrm{In}^{3+}$ after intraperitoneal injection of DPPC-cholesterol vesicles containing entrapped ${ }^{111} \mathrm{In}^{3+}$. The C57BL/ 6 mice used were 53 days old and had a mean weight of $17.3 \mathrm{~g}$; blood volume was assumed to be $1.3 \mathrm{ml}$. $\times$, Skin; $\bullet$, blood; $O$, liver; $\square$, intestine; $\Delta$, kidney; $\square$, spleen; $\Delta$, lung.

and was not removed by washing the tissue with $0.9 \% \mathrm{NaCl}$, indicating binding of the ${ }^{111} \mathrm{In}^{3+}$ to tissue at or near the site of injection. No significant excretion of ${ }^{111} \mathrm{In}^{3+}$ was detected in the $24 \mathrm{hr}$ after administration of $\mathrm{NTA} /{ }^{111} \mathrm{In}^{3+}$ to other mice.

\section{DISCUSSION}

The versatility of liposomes as carriers of pharmacologically active agents has become increasingly apparent. Entrapment of therapeutic materials in various types of lipid vesicles can in principle not only afford protection for the material but also allow the rate and route of its uptake to be altered. Attempts to determine the fate of administered liposomes by classical radioactive tracer methods have been complicated by the difficulty in distinguishing entrapped radioactivity from that released from the liposomes. Alternative methods for studying the fate of liposomes have been sought. McDougall et al. (17) used electron paramagnetic resonance spectra to characterize the integrity of unilamellar vesicles, containing the spin label tempocholine, before injection and after their recovery in mouse blood. More recently, Weinstein et al. (18) utilized the self-quenching fluorescent properties of the entrapped dye 6-carboxyfluorescein to distinguish between material still remaining in vesicles and that released intracellularly in in vitro cell suspension systems.

The approach developed in this paper for establishing the structural integrity of vesicles by monitoring the molecular motion of ${ }^{111} \mathrm{In}^{3+}$ has broad applicability in vitro as well as in vivo. In this method, ${ }^{111} \mathrm{In}^{3+}$ in the presence of a suitable chelator is added to the aqueous phase during liposome preparation. The ability to assess membrane integrity would not be affected by the method used for formation of liposomes, the nature of the membrane constituents, or the presence of other entrapped components.

The in vitro experiments using entrapped ${ }^{111} \mathrm{In}^{3+}$ clearly show that the PAC technique is capable of detecting alterations in membrane structure occurring upon the addition of serum to vesicles. These findings are in agreement with a previous report (19) indicating that some liposomes that are stable to leakage of captured ions in physiological salt solutions become 
more leaky in the presence of fresh serum. The greater stability of DPPC-cholesterol vesicles in the presence of serum was anticipated based on previous reports that inclusion of cholesterol in the bilayer results in a decrease in premeability of the liposomes (20-22). This points out the usefulness of PAC for rapid initial in vitro testing of liposomes of varying compositions to assess their structural stability. This technique could screen liposomes and eliminate from in vivo testing programs those preparations that would undergo unsatisfactory rates of destruction upon entering the bloodstream.

More important, however, is the usefulness of the procedures described in this paper for application to in vivo experiments. We have shown that by using PAC it is possible to monitor continuously the percentage of vesicles remaining intact in vivo. This is a parameter not readily determinable by other techniques. In addition, the PAC measurements suggest that vesicles can remain intact in various tissues for extended periods and, thereby, can slowly release the encapsulated material at those sites. Our data do not allow determination of rates of vesicle destruction in specific organs or tissues. However, the present method can in principle be adapted to investigate the integrity of vesicles in any specific area of the body by using lead shielding to block out other areas. The data could also be combined with tissue distributions obtained by using wholebody scintillation scanners to yield more complete kinetic information. Alternatively, information on vesicle destruction at specific sites can be obtained in future studies through injection of vesicle preparations containing sufficiently high levels of entrapped ${ }^{111} \mathrm{In}^{3+}$ such that, upon sacrifice of the animals, PAC measurements could be made on isolated organs and tissues.

We gratefully acknowledge the encouragement and support of Prof. John D. Baldeschwieler. We also thank our colleagues in this laboratory, particularly Dr. R. C. Gamble for his stimulating discussions and A. Y. Hwang for her helpful technical assistance. This investigation was supported by the National Institutes of Health Grant GM-21111-03 and National Science Foundation Grant GP-38855X-3. This is contribution 5596 from the Arthur Amos Noyes Laboratory of Chemical Physics.
1. Gregoriadis, G. \& Buckland, R. A. (1973) Nature 244, 170172.

2. Weissman, G., Bloomgarden, D., Kaplan, R., Hoffstein, C., Collins, T., Gottlieb, A. \& Nagle, D. (1975) Proc. Natl. Acad. Sci. USA 72, 88-92.

3. Braidman, I. \& Gregoriadis, G. (1976) Biochem Soc. Trans. 4, 259-261.

4. Rahman, Y.-E., Rosenthal, M. W. \& Cerny, E. A. (1973) Science 180, 300-302.

5. Gregoriadis, G., Swain, C. P., Wills, E. J. \& Tavill, A. S. (1974) Lancet i, 1313-1316.

6. Gregoriadis, G. (1977) Nature 265, 407-411.

7. Fendler, J. H. \& Romero, A. (1977) Life Sci. 20, 1109-1120

8. Poste, G., Papahadjopoulos, D. \& Vail, W. J. (1976) in Methods in Cell Biology, ed. Prescott, D. M. (Academic Press, New York), Vol. 14, pp. 33-71.

9. Tyrrell, D. A., Heath, T. D., Colley, C. M. \& Ryman, B. E. (1976) Biochim. Biophys. Acta 457, 259-302

10. Meares, C. F., Sundberg, M. W. \& Baldeschwieler, J. D. (1972) Proc. Natl. Acad. Sci. USA 69, 3718-3722.

11. Leipert, T. K., Baldeschwieler, J. D. \& Shirley, D. A. (1968) Nature 220, 907-909.

12. Meares, C. F. \& Westmoreland, D. G. (1971) Cold Spring Harbor Symp. Quant. Biol. 36, 511-516.

13. Goodwin, G. A., Meares, C. F. \& Song, C. H. (1972) Radiology 105, 669-702

14. Dapergolas, G., Neerunjun, E. D. \& Gregoriadis, G. (1976) FEBS Lett. 63, 235-239.

15. Hosain, F., McIntyre, P. A., Poulose, K., Stern, H. S. \& Wagner H. N. (1969) Clin. Chim. Acta 24, 69-75.

16. Juliano, R. L. \& Stamp, D. (1975) Biochem. Biophys. Res. Commun. 63, 651-658.

17. McDougall, I. R., Dunnick, J. K., McNamee, M. G. \& Kriss, J. P. (1974) Proc. Natl. Acad. Sci. USA 71, 3487-3491.

18. Weinstein, J. N., Yoshikami, S., Henkart, P., Blumenthal, R. \& Hagins, W. A. (1977) Science 195, 489-492.

19. Kimelberg, H. K., Mayhew, E. \& Papahadjopoulos, D. (1975) Life Sci. 17, 715-724.

20. Papahadjopoulos, D., Nir, S. \& Ohki, S. (1972) Biochim. Biophys. Acta 266, 561-583.

21. de Gier, J., Manderloot, J. G. \& van Deenen, L. L. M. (1968) Biochim. Biophys. Acta 150, 666-675.

22. Papahadjopoulos, D., Cowden, M. \& Kimelberg, H. (1973) Biochim. Biophys. Acta 330, 8-26. 